\title{
Effectiveness of home pharmaceutical interventions in metabolic syndrome: a randomized controlled trial
}

\author{
Maria da Glória Batista de Azevedo ${ }^{1 *}$, Roseana Souza Pedrosa ${ }^{3}$, Caroline Mapurunga Aoqui², \\ Rand Randall Martins ${ }^{2}$, Toshiyuki Nagashima Junior ${ }^{3}$
}

\begin{abstract}
${ }^{1}$ Post-graduate Program in Pharmaceutical Sciences, State University of Paraiba, Campina Grande, PB, Brazil, ${ }^{2}$ Pharmacy Department, Federal University of Rio Grande of Norte, Natal, RN, Brazil, ${ }^{3}$ Academic Health Unit, Federal University of Campina Grande, Cuité, PB, Brazil
\end{abstract}

\begin{abstract}
Metabolic syndrome (MetS) is a group of different risk factors that raises the chances of develop several health problems such, as cardiovascular disease and diabetes. There are few cases in literature of studies that specifically address the use of pharmaceutical care in MetS. The aim of study was to evaluate the effectiveness of home pharmaceutical interventions in patients with this syndrome. The randomized clinical trial was conducted in subjects with diagnosis of MetS treated in a basic unit of health from Cuité, Paraíba. The patients were randomized in a 1:1 ratio to two groups: intervention (IG) and control (CG). The IG received monthly individual pharmaceutical interventions, while the CG did not. The effectiveness of the intervention protocol was measured after six months, comparing the hemodynamic values, anthropometric, biochemistry, cardiovascular risk, medication adherence, drug related problems (DRP) and quality of life. The sample consisted of 63 individuals (33 IG and 30 CG) and older than 60 years. The majority of pharmaceutical interventions were educational and/or behavioral. In the intervention group, significant differences were observed in the parameters systolic and diastolic blood pressure, triglycerides, medication adherence and DRP. The pharmaceutical interventions at home were effective in improving medication adherence, decreasing DRPs and helping to control components of the metabolic syndrome.
\end{abstract}

Uniterms: Metabolic syndrome/study. Pharmaceutical care/home. Pharmaceutical interventions. Drug related problems.

\section{INTRODUCTION}

Metabolic syndrome (MetS) is a low-grade chronic inflammation state resulting from the interaction of genetic and environmental factors. MetS is constituted of components such as insulin resistance, atherogenic dyslipidemia, hypertension, central obesity, endothelial dysfunction, genetic susceptibility, hypercoagulable state and chronic stress (Kaur, 2014). Several studies have demonstrated the strong relationship between MetS and occurrence of cardiovascular diseases (CVD). MetS doubles the incidence of heart attack, type 2 diabetes and increases the risk of mortality from CVD (Grundy, 2012; Shin et al., 2013; O’Neill, O’Driscoll, 2015).

\footnotetext{
*Correspondence: M. G. B. Azevedo. Programa de Pós-graduação em Ciências Farmacêuticas. Universidade Estadual da Paraíba. Sítio Olho D’água da Bica, s/n, Zona rural, 58175-000 - Cuité, PB, Brasil. Phone: +55 83 33721933; +5583 999066628. E-mail: gloria.farmacia@hotmail.com
}

The multifactorial characteristic of MetS requires a complex clinical management. Treatment of the MetS consists of healthy lifestyle (adequate diet and physical activity), risk factor prevention and individualized drug regimen. The aim is decrease the MetS's progression, demanding, in most cases, polypharmacy (Kaur, 2014; Plaster et al., 2012). In this way, patient education through health professionals encourages changes in lifestyle and increases medications adherence (Gerstel et al., 2013). Pharmacist collaborates in the education process through guidance on the appropriate use of medicines, especially in primary care (Mendes, 2012, OPS/OMS, 2013; Brasil, 2014).

Recently in Brazil, new public policies stimulate the pharmaceutical action to solve problems related to the medicines. Inappropriate use of medications is the main cause of aggravation of diseases such as MetS. In view of this, the Federal Council of Pharmacy, through resolutions 
585 and 586/2013, encourages the participation of pharmacists in multidisciplinary teams for the monitoring of chronic diseases, particularly in primary care (Mendes, 2012; Brasil, 2014).

Home care is essential in the treatment of chronic diseases. Home pharmaceutical intervention identifies the main barriers to the correct use of medicines, in addition to collaborating with the physician increasing the effectiveness and safety of the medicine (Zermansky et al., 2006).

Meta-analysis involving 14,224 patients showed effectiveness of the pharmaceutical interventions related to health education, collaboration with the physician and guidance on medication use (Santschi et al., 2014). The blood pressure values for example, this article showed reductions in the order of $8.0 \mathrm{mmHg}$ (systolic) and $4.0 \mathrm{mmHg}$ (diastolic) due to the performance of the pharmacist. Another meta-analysis (Chisholm-Burns et al., 2010) concluded the pharmacist positively affects glycated hemoglobin values. In Brazil, a pharmaceutical care program significantly reduced glycated hemoglobin values (Mourão et al., 2013). However, the literature is scarce on the impact of home pharmaceutical care on metabolic syndrome.

Thus, the aim of this study was to evaluate the effectiveness of home pharmaceutical interventions in Brazilian primary care patients with MetS.

\section{MATERIAL AND METHODS}

\section{Type of study}

This is a randomized controlled study conducted in patients seen by primary care at Cuité city $(20.312$ inhabitants), located in the northeastern Brazil. The study was a clinical trial with patient follow-up. These were recruited in first month of the study (June, 2014) in the main municipal unit of primary care responsible for more than 800 families. It was characterized as a pharmacotherapeutic follow-up of patients with duration of six months, organized with intervention and control group. Details of the study design, participant enrollment, and intervention components are described below.

\section{Selection of patients and randomization}

The study sample included patients of both genders aged over 18 years and diagnosed with MetS (NCEP, 2001) by a primary care physician in the last 30 days (June, 2014). Pregnant women and people with mental disorders were excluded from study. Were initially eligible 105 patients based on patient chart review; those patients who did not found, did not attend the blood collect for biochemical analysis or refused to participate of the research were removed. Subsequently, patients were randomized to one of two groups (intervention group or control group) based on the number assigned to their folders using the "online random sequence generator" (Haahr, 2014). The patients in the intervention group (GI) were numbered from 1 to 35 and 36 to 65 for the control group (CG) (Adibe, Aguwa, Ukwe, 2013). The Figure 1 shows the study design.

\section{Data collection}

For home data collection, Pharmacotherapy Workup Notes (Cipolle, Strand, Morley, 2004) was used by trained pharmacist. Demographics data (gender, age, income monthly/per capita and education level), anthropometric parameters (body mass index [BMI] and waist circumference), hemodynamic parameters (blood pressure and Framingham cardiovascular risk (D'Agostino et al., 2008)) and biochemical parameters (blood glucose and lipid profile - total cholesterol, LDL, HDL, triglycerides) were collected. In addition to drug-related problems evaluation, the Brief Medication Questionnaire (Ben, Neumann, Mengue, 2012) was also used to assess medicine compliance and WHOQOL-bref (WHOQOL, 1995 ) for quality of life, both versions validated in portuguese. The data were collected at the beginning and at the end of the trial period (six months) in both groups (July, 2014 to December, 2014).

The study did not use sample size calculation. The sample was formed by all patients diagnosed with MetS during the period established for patient enrollment in study.

\section{Intervention}

The IG was subjected to a protocol of home visits, which consisted of 2 sessions of 40 minutes each ( 1 st and 15 th days of the study) and 6 sessions of 20 minutes each (respectively 30, 60, 90, 120, 150 and 180 days). The CG had researcher visits on the 1st and on the 180th day, only for data collection. Blood samples for biochemical analysis were collected in the first and last weeks of the study by a pharmaceutical researcher in clinical laboratory. The anthropometric date and blood pressure measurements of patients were performed also in the first and last weeks of the study by pharmacist at home.

The interventions consisted of guidance to patients and provision of information to other health professionals, as needed. The patient education techniques adopted were delivery of an illustrated leaflet on healthy nutrition and 


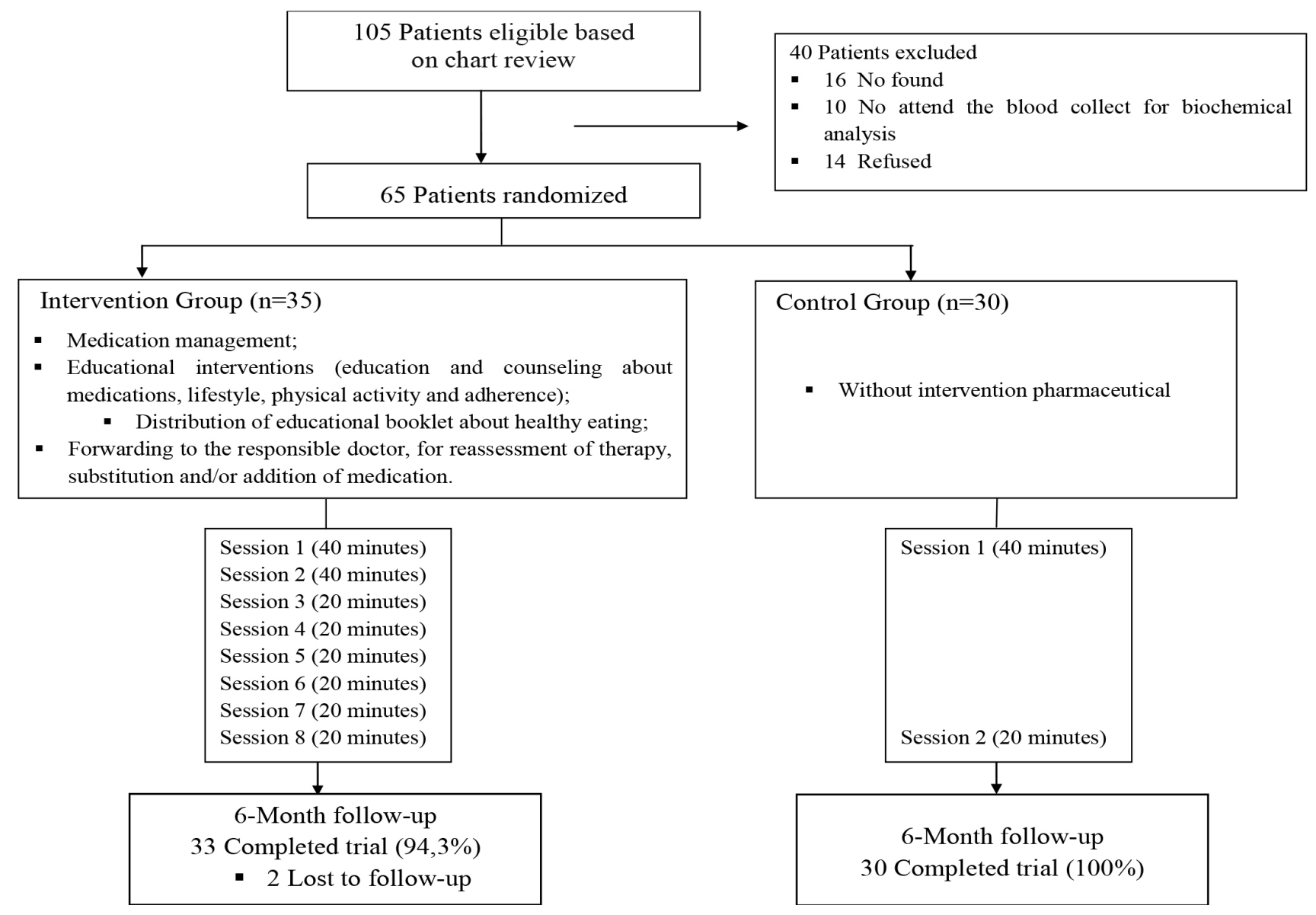

FIGURE 1 - Flowchart of the formation of the study sample.

physical activity practice, disease, treatment and especially medicines in use information. The visits were performed by qualified pharmacist researcher and trained to carry out the proposed interventions.

In the initial visits (sections 1 and 2) were established the relationship with patient and information collected were demographic, experiences with medicines, current health status, medical history, nutritional status, current and past medications and information complementary such as the use of other substances, immunizations, allergies and alerts. With this data the drugs related problems have been identified (DRPs). Interventions (sections 3-8) were performed to resolve DRPs detected, to therapeutic targets and to prevent new DRPs. At the end of each session, next visit was scheduled in 30 days.

The patient's interventions consisted of medication review, counseling on proper storage of medicines at home, medication education and counseling, incentive to medication compliance, sodium restriction, moderation in consumption of carbohydrates, replacement saturated fat and physical activity (walking in moderate rhythm for 30 minutes at least three times a week). Specific and individualized guidance for DRP resolution were provided, especially those related to prescriber's contribution, highlighting ineffective drug therapy and untreated health problem. The interventions were orally conferred comprising the trinomial pharmaceutical-patientprescriber. The Pharmacotherapy Workup, developed by Cipolle, Strand, Morley (2004), was the clinical method used for the detection, planning and intervention of DRP. All interventions were performed by researcher, without institutional link with the health service.

The effectiveness of the intervention protocol was measured by comparing the measured values at baseline and after follow-up of blood pressure (BP), fasting glucose, total cholesterol, triglycerides, HDL cholesterol, LDL cholesterol, waist circumference (WC), body mass index (BMI), cardiovascular risk, medication adherence, number of DRP (including new DRP) and quality of life.

\section{Statistical Analysis}

Statistical analysis was performed using Stata software release 12 (Stata Corporation, College Station, 
TX, USA). The variables are presented as absolute and relative frequencies, mean and standard deviation, where appropriate. For comparison between CG and IG at baseline was used the Student $t$ - test between the means and Fisher's exact test for proportions. Each parameter was analyzed by multiple regression of the differences between initial and final values of each group, being the initial parameter values adjusted for control of confounding. Significance was set asp $<0.05$.

\section{Ethical approval}

The study was approved by the Research and Ethics Committee of the State University of Paraiba, protocol number 31028914.2.0000.5187/14.

\section{RESULTS}

In baseline, there were no statistically differences between the groups (CG vs IG) in relation to demographic, biochemical, hemodynamic and anthropometric characteristics. Likewise, medication compliance, quality of life and cardiovascular risk. The sample consisted of 63 subjects with a median age of 62 years (IG) and 68 years (CG). There was a predominance of females, in both groups, 26 women (79.8\%) in the intervention group and $22(73.3 \%)$ in the control group (Table I).

Clinical characteristics (Table I) and therapeutic profile (Table II) showed no differences between groups at baseline, except for the slightly higher DRP mean in the GI (reflection of relatively small sample size).

TABLE I - Baseline demographic and clinical characteristics of the studied patients in the control and intervention groups, $\mathrm{n}(\%)$, mean \pm S.D.

\begin{tabular}{|c|c|c|c|}
\hline Variable & Control group & Intervention group & $\mathbf{p}$ \\
\hline Patients (n) & 30 & 33 & - \\
\hline Male:Female & $8(26.7 \%): 22(73.3 \%)$ & $7(21.2 \%): 26(79.8 \%)$ & 0.800 \\
\hline Age (years) & $66.9+/-9.7(43-82)$ & $61.4+/-12.2(39-80)$ & 0.056 \\
\hline $\mathrm{BMI}\left(\mathrm{Kg} / \mathrm{m}^{2}\right)$ & $26.5+/-4.2(16.2-34.4)$ & $28.5+/-4.0(21.9-38.4)$ & 0.061 \\
\hline Waist circumference & $98.1+/-8.2(79-118)$ & $101.3+/-8.5(87-120)$ & 0.133 \\
\hline Framingham 10-year CHD risk & $20.4+/-8.4(5.3-30)$ & $17.8+/-9.2(2-30)$ & 0.328 \\
\hline Monthly household income (\$) & $325.8+/-142.5(203.6-814.4)$ & $366.2+/-142.5(203.6-610.8)$ & 0.575 \\
\hline Per capita monthly household income (\$) & $101.8+/-20.4(40.7-407.2)$ & $122.2+/-20.4(40.7-305.4)$ & 0.607 \\
\hline \multicolumn{4}{|l|}{ Level of education } \\
\hline No formal education & $11(36.7 \%)$ & $12(36.4 \%)$ & 0.841 \\
\hline Primary education level & $19(63.3 \%)$ & $18(54.5 \%)$ & 0.611 \\
\hline Secondary education level & 0 & $3(9.1 \%)$ & 0.101 \\
\hline $\mathrm{SBP}(\mathrm{mmHg})$ & $135.5+/-20.4(110-200)$ & $142.6+/-14.6(120-170)$ & 0.134 \\
\hline $\mathrm{DBP}(\mathrm{mmHg})$ & $80.2+/-10.0(60-100)$ & $85.3+/-10.1(70-110)$ & 0.056 \\
\hline Fasting glycemia $(\mathrm{mg} / \mathrm{dL})$ & $98.3+/-33.6(70-218)$ & $114.1+/-54.2(77-311)$ & 0.171 \\
\hline Total cholesterol (mg/dL) & $188.6+/-40.6(120-269)$ & $180.8+/-42.9(128-377)$ & 0.455 \\
\hline LDL-C (mg/dL) & $107.2+/-36.0(47-175)$ & $91.2+/-35.9(47-175)$ & 0.455 \\
\hline HDL-C (mg/dL) & $42.9+/-12.8(28-79)$ & $44.7+/-13.0(20-85)$ & 0.018 \\
\hline Triglycerides $(\mathrm{mg} / \mathrm{dL})$ & $199.4+/-85.4(61-473)$ & $225.6+/-102.3(96-618)$ & 0.270 \\
\hline Brief Medication Questionnaire Adherence Scale & $15(50 \%)$ & $16(48.5 \%)$ & 0.869 \\
\hline High & $3(10 \%)$ & $4(12.1 \%)$ & \\
\hline Medium & $12(40 \%)$ & $12(36.4 \%)$ & \\
\hline Low & $15(50 \%)$ & $17(51.5 \%)$ & \\
\hline Quality of Life & $64.7+/-7.8(47.2-77.3)$ & $63.7+/-7.2(47.2-75.1)$ & 0.591 \\
\hline
\end{tabular}

S.D Standard deviation. BMI body mass index; CHD coronary heart disease; LDL-C low-density lipoprotein cholesterol; HDL-C high-density lipoprotein cholesterol; SBP systolic blood pressure; DBP diastolic blood pressure. 
TABLE II - Initial therapeutic profile and DRP of control and intervention group, $\mathrm{n}(\%)$, mean \pm S.D.

\begin{tabular}{|c|c|c|c|}
\hline Variable & Control group & Intervention group & $\mathbf{p}$ \\
\hline Medications numbers & $3.2+/-1.7(1-7)$ & $4.1+/-1.9(0-8)$ & 0.055 \\
\hline \multicolumn{4}{|l|}{ Anatomical Therapeutic Chemical Code } \\
\hline C10A - Lipid modifying agents, Plain & $20(20.85)$ & $31(21.8 \%)$ & 0.874 \\
\hline C03A - Low-ceiling diuretics, Thiazides & $13(13.5 \%)$ & $10(7.0 \%)$ & 0.118 \\
\hline A10B - Blood glucose lowering drugs, excl. Insulins & $10(10.4 \%)$ & $20(14.1 \%)$ & 0.434 \\
\hline C09A - ACE inhibitors, Plain & $9(9.4 \%)$ & $11(7.8 \%)$ & 0.646 \\
\hline C09C - Angiotensin II antagonists, Plain & $9(9.4 \%)$ & $10(7.0 \%)$ & 0.627 \\
\hline $\begin{array}{l}\text { M01A - Antiinflammatory and antirheumatic products, Non- } \\
\text { steroids }\end{array}$ & $5(5.2 \%)$ & $3(2.1 \%)$ & 0.274 \\
\hline $\begin{array}{l}\text { A02B - Drugs for peptic ulcer and gastro-esophageal reflux } \\
\text { disease }\end{array}$ & $3(3.1 \%)$ & $10(7.0 \%)$ & 0.251 \\
\hline Others & $27(28.1 \%)$ & $47(33.1 \%)$ & 0.476 \\
\hline Total & $96(100 \%)$ & $142(100 \%)$ & - \\
\hline Drug-related problems (DRP) & $1.0+/-1.2(0-4)$ & $2.2+/-1.5(0-5)$ & 0.004 \\
\hline \multicolumn{4}{|l|}{ Categories of DRP } \\
\hline The patient forgets to take the medication (Adherence) & $8(25.8 \%)$ & $9(12.3 \%)$ & 0.162 \\
\hline $\begin{array}{l}\text { Requires additional pharmacotherapy to attain synergistic or } \\
\text { additive effects (Indication) }\end{array}$ & $6(19.4 \%)$ & $7(9.6 \%)$ & 0.337 \\
\hline Inappropriate frequency resulting in low dose (Effectiveness) & $3(9.7 \%)$ & $8(10.9 \%)$ & 1 \\
\hline The problem is refractory to the drug product (Effectiveness) & $2(6.5 \%)$ & $11(15.1 \%)$ & 0.214 \\
\hline The patient prefers not to take the medication (Adherence) & $2(6.5 \%)$ & $7(9.6 \%)$ & 0.714 \\
\hline $\begin{array}{l}\text { A medical condition requires the initiation of drug therapy } \\
\text { (Indication) }\end{array}$ & $2(6.5 \%)$ & $7(9.6 \%)$ & 0.714 \\
\hline Others & $8(25.8 \%)$ & $24(32.9 \%)$ & 0.213 \\
\hline Total & $31(100 \%)$ & $73(100 \%)$ & - \\
\hline
\end{tabular}

DRP's compliance prevailed over effectiveness and indication.

At baseline, IG presented 27 patients $(81.8 \%)$ with one or more DRP and 6 patients $(18.2 \%)$ without DRP. After 6 month follow-up, 21 patients (63.6\%) still presented DRP, considering the unresolved and/or news cases and 12 patients (36.4\%) without DRP. The CG remained stable at baseline and after follow-up: 19 patients $(63.3 \%)$ with DRP and 11 patients $(36.7 \%)$ without; 20 patients $(66.7 \%)$ with DRP and 10 patients $(33.3 \%)$ without DRP, respectively.

Aiming to solve the DRP found and prevent future DRP, 76 pharmaceutical interventions (PI) were performed. Of these PIs, 49 (64.5\%) were related to conduct on educational and behavioral: medication management (medication review of patient, assessment of medication compliance, orientation about appropriate storage of medicines at home); educational interventions to patients (education and counseling about medications, lifestyle, physical activity and compliance); distribution of educational booklet about healthy food. Twenty PI $(26.3 \%)$ involved the physician requesting reassessment of therapy, replacement and/or addition of medication. The referral for clinical evaluation of potential untreated health problem occurred in 7 situations $(9.2 \%)$. Interventions directed at the IG totaled an average of 2.3 /patient. Interventions performed with the physician showed an acceptance of $63 \%(n=17)$, acceptability of the patient was not measured to not interfere in methodology.

Table III depicts the effectiveness of PI in improving biochemical and hemodynamic profiles, medication compliance, quality of life and the mean DRP at baseline and follow-up. In IG, there were significant differences $(p<0.05)$ in systolic blood pressure $(p=0.003)$, diastolic blood pressure $(\mathrm{p}=0.043)$, triglycerides $(\mathrm{p}=0.034)$, adherence $(p=0.026)$ and DRP $(p=0.001)$. The control group in turn, showed similar values in both moments, without significant differences in all parameters. 
M. G. B. Azevedo, R. S. Pedrosa, C. M. Aoqui, R. R. Martins, T. Nagashima Junior

TABLE III - Comparison of parameters at baseline and after 6 month follow-up, $\mathrm{n}(\%)$, mean \pm S.D.

\begin{tabular}{lcccccc}
\hline \multirow{2}{*}{ Variable } & \multicolumn{3}{c}{ Control group } & \multicolumn{3}{c}{ Intervention group } \\
\cline { 2 - 7 } & Baseline & $\mathbf{6}$ months & p & Baseline & 6 months & p \\
\hline BMI $\left(\mathrm{Kg} / \mathrm{m}^{2}\right)$ & $26.5+/-4.2$ & $25.9+/-6.4$ & 0.484 & $28.5+/-4.0$ & $28.7+/-4.1$ & 0,091 \\
Waist circumference & $98.1+/-8.2$ & $98.5+/-8.5$ & 0.093 & $101.3+/-8.5$ & $101.5+/-8.9$ & 0.699 \\
Framingham 10-year CHD risk & $20.4+/-8.4$ & $22.0+/-8.0$ & 0.106 & $17.8+/-9.2$ & $16.3+/-8.9$ & 0.081 \\
SBP (mmHg) & $135.5+/-20.4$ & $141.3+/-21.5$ & 0.285 & $142.6+/-14.6$ & $131.2+/-19.1$ & 0.003 \\
DBP (mmHg) & $80.2+/-10.0$ & $86.0+/-13.1$ & 0.06 & $85.3+/-10.1$ & $81.4+/-9.4$ & 0.043 \\
Fasting glycemia (mg/dL) & $98.3+/-33.6$ & $113.2+/-39.8$ & 0.122 & $114.1+/-54.2$ & $106.6+/-31.9$ & 0.482 \\
Total cholesterol (mg/dL) & $188.6+/-40.6$ & $185.0+/-43.0$ & 0.584 & $180.8+/-42.9$ & $189.2+/-32.4$ & 0.271 \\
LDL-C (mg/dL) & $107.2+/-36.0$ & $104.1+/-33.7$ & 0.601 & $91.2+/-25.2$ & $102.1+/-27.0$ & 0.0717 \\
HDL-C (mg/dL) & $42.9+/-12.8$ & $39.7+/-12.6$ & 0.327 & $44.7+/-13.0$ & $50.0+/-28.6$ & 0.096 \\
Triglycerides (mg/dL) & $199.4+/-85.4$ & $221.1+/-85.9$ & 0.329 & $225.6+/-102.3$ & $183.4+/-52.4$ & 0.034 \\
Brief Medication Questionnaire & $15(50 \%)$ & $14(46.7 \%)$ & 0.717 & $16(48.5 \%)$ & $22(66.7 \%)$ & 0.026 \\
adherence scale & & & & & & \\
Quality of Life & $64.7+/-7.8$ & $64.9+/-7.7$ & 0.927 & $63.7+/-7.2$ & $64.5+/-7.0$ & 0.634 \\
DRP & $1.0+/-1.2$ & $1.1+/-1.3$ & 0.752 & $2.2+/-1.5$ & $0.9+/-1.0$ & 0.001 \\
Medications numbers & $3.2+/-1.7$ & $3.1+/-1.8$ & 0.828 & $4.1+/-1.9$ & $3.7+/-1.6$ & 0.340 \\
\hline
\end{tabular}

DRP Drug-related problems.

\section{DISCUSSION}

As evidenced, the results of this study confirm the efficacy of pharmaceutical interventions at home in the control of lipid and blood pressure levels in patients with MetS. We observed in IG that the increase in medication compliance implies to decrease in mean of DRP. This result is similar to that reported by other authors who showed pharmaceutical interventions as beneficial for blood pressure and triglycerides (Santsch et al., 2011; Santsch et al., 2012; Charrois et al., 2012; Cheema, Sutcliffe, Singer, 2014; Wal et al., 2013; Firmino et al., 2015). However, these studies have been limited a hypertension and diabetes, MetS is rarely investigated. Besides, the methodology did not consider home interventions. The merit of this study is identification, monitoring and education of patients with MetS. We using a broad approach, contrasting to pharmaceutical care protocols restricted to hypertension, diabetes and dyslipidemia.

The homecare services are a valid strategy for the monitoring of chronic diseases through identification of DRP and adverse reactions, improvement in lipid profiles, blood pressure and quality of life (Peterson et al., 2004; Sino et al., 2013). The MetS is characterized as a complex disorder whose diagnosis is not well established and treatment does not integrate conventional care protocols (Hammad et al., 2011). The literature is scarce about the role of home pharmaceutical service in the treatment of patients with MetS, although some studies suggest benefits when isolated syndrome components were approached. The homecare program developed by Peterson and collaborators (2004) has been successful in reducing total cholesterol in dyslipidemic patients. This study concluded that pharmacists are important to detection and prevention of low compliance. Patients are made aware benefits of diet and lifestyle changes; as well stimulate use of lipid-lowering drug therapy and adequate follow-up.

Most of interventions performed involved education and stimulation of medicine compliance, which increased at end of the study. The predominant DRP in both groups involves forgetting or misuse of medication because misconception of the prescription; in others words, absence of medication compliance. As half of the patients were categorized as non-adherent to medication treatment, the prevalence of DRP related to adherence is well established. Estimated that non-medication adherence is responsible for $10 \%$ of hospital admissions for hypertension and diabetes, besides causingmajor spending on health, worsening in quality of life and prognosis of these diseases (Russel, Conn, Jantarakupt, 2006; Jin et al., 2008; Doggrell, 2010). Some factors present in this sample are commonly associated with low medication 
adherence as aging, poor education and income. Some of these factors, especially aging and poor education make it difficult to understand written or oral explanations. As noted in our study, brief home explanations are effective in reducing this deficiency.

During the visits, the on-site observation of the medicines was evidenced for a better orientation related to the use and storage. The accumulation of home medications may be associated with worse clinical outcomes and lower adherence to treatment (Sorensen et $a l ., 2005)$, as well as higher frequency of self-medication, administration errors, drug interactions and adverse reactions (Wieczorkiewicz, Kassamali, Danziger, 2013; Ocan et al., 2014). For example, it was common in this sample a bad organization of home stock, difficulties in the identification of drugs and their dosage, especially due advanced age and low education. Often, the patient referred the product by color and size, but could not remember the name of the active ingredient or its therapeutic indication. Observed that the orientation about schedules and appropriate use of medications was facilitated with the product in hands, likewise that was possible to demonstrate the local and the appropriate organization of medications at home.

Observations of health professionals in the home environment can provide important contextual details that help understand the problems and how can be solved. The interventions can be developed, considering the individual limitation, and integrated with successfully in home (Gilmartin, 2013).

Improving medication adherence not equally reflected in all parameters. Some components of MetS are more susceptible to pharmaceutical interventions such as blood pressure and triglyceride levels, because they respond more rapidly to pharmacotherapy. Reducing waist circumference, fasting glucose and HDL cholesterol require more pronounced changes in lifestyle and dietetics habits, demanding a response time higher than a six-month follow-up (Hammad et al., 2011). Thus, the resolution of problems related to medication adherence directly affects the reduction of specific parameters.

An important aspect of this study was the relatively short time taken in the interventions. After the first two meetings of about 40 minutes and dedicated to data collection, short subsequent meetings (20 minutes) every 30 days were sufficient to promote improvements some parameters.

However the study has some limitations, mainly related to the small sample size and a short-term followup. The sample size may decrease the effectiveness in detecting differences between the groups and the generalization can be restricted to patients with advanced age, low income and education. Therefore, longer studies and larger numbers of patients are necessary to evaluate the long-term benefits in other populations.

\section{CONCLUSIONS}

The results obtained in this study showed that the pharmaceutical interventions in the home environment were effective, resulting in increased medication adherence (18.2\% increase) and decreased DRP mean in the sample (59.0\% decrease), as well as reduction of blood pressure $(8.0 \%)$ and serum triglycerides (18.7\%).

The strategy education pharmaceutical centered in the home orientation establish a pharmacist-patientmedication relationship. This relationship stimulates self-care both in relation to medicine and non-medicine treatment. Benefits of an appropriate pharmaceutical orientation are diverse: patients can recognize the need to medicines to maintain their health and well-being, the interaction between health professional and patient becomes more dynamic by establishing an environment of trust, capable to increase adherence to treatment (Andrade, Silva, Freitas, 2004).

Also is evident the importance of a multidisciplinary team committed with integral care and observing the individuality of each patient, because when performs interventions according to their skills and knowledge can generate results even more satisfactory.

\section{ACKNOWLEDGEMENTS}

The authors are grateful to all patients and Health Basic Unit and acknowledge the State University of Paraiba and Federal University of Campina Grande Brazil for its financial support this study.

\section{REFERENCES}

ADIBE, M.O.; AGUWA, C.N.; UKWE, C.V. Cost-utility analysis of pharmaceutical care intervention versus usual care in management of Nigerian patients with type 2 diabetes. Value in Health Regional Issues, v.2, n.2, p.189198, 2013.

ANDRADE, M.A.; SILVA, M.V.S.; FREITAS, O. Assistência farmacêutica como estratégia para o uso racional de medicamentos em idosos. Semina: Ciênc. Biol. Saúde, v.25, n.1, p.55-64, 2004. 
BEN, A.J.; NEUMANN, C.R.; MENGUE, S.S. Teste de Morisky-Green e Brief Medication Questionnaire para avaliar adesão a medicamentos. Rev. Saúde Pública, v.46, n.2, p. 279-289, 2012.

BRASIL. Ministério da Saúde. Departamento de Assistência Farmacêutica e Insumos Estratégicos. Serviços farmacêuticos na atenção básica à saúde. Brasília: Ministério da Saúde, 2014. 108p.

CHARROIS, T.L.; ZOLEZZI, M.; KOSHMAN, S.L.; PEARSON, G.; MAKOWSKY, M.; DUREC, T.; TSUYUKI, R.T. A systematic review of the evidence for pharmacist care of patients with dyslipidemia. Pharmacotherapy, v.32, n.3, p.222-233, 2012.

CHEEMA, E.; SUTCLIFFE, P.; SINGER, D.R.J. The impact of interventions by pharmacists in community pharmacies on control of hypertension: a systematic review and meta-analysis of randomized controlled trials. Br. J. Clin. Pharmacol., v.78, n.6, p.1238-1247, 2014.

CIPOLLE, R.J.; STRAND, L.M.; MORLEY, P.C. Pharmaceutical care practice: the clinician's guide. 2. ed. New York: Mcgraw-Hill, 2004. 624p.

CHISHOLM-BURNS, M.A.; KIM LEE, J.; SPIVEY, C.A.; SLACK, M.; HERRIER, R.N.; HALL-LIPSY, E.; GRAFF ZIVIN, J.; ABRAHAM, I.; PALMER, J.; MARTIN, J.R.; KRAMER, S.S.; WUNZ, T. US pharmacists' effect as team members on patient care: systematic review and metaanalyses. Med. Care, v.48, n.10, p.923-933, 2010.

D'AGOSTINO, R.B.; VASAN, R.S.; PENCINA, M.J.; WOLF, P.A.; COBAIN, M.; MASSARO, J.M.; KANNEL, W.B. General cardiovascular risk profile for use in primary care: the Framingham heart study. Circulation, v.117, n.6, p.743$753,2008$.

DOGGRELL, S.A. Adherence to medicines in the older-aged with chronic conditions. Drugs Aging, v.27, n.3, p.239-254, 2010 .

EXECUTIVE SUMMARY OF THE THIRD REPORT OF THE NATIONAL CHOLESTEROL EDUCATION PROGRAM. NCEP. Expert panel on detection, evaluation, and treatment of high blood cholesterol in adults (adult treatment panel III). JAMA, v.285, n.19, p.2486-2497, 2001.
FIRMINO, P.Y. M.; VASCONCELOS, T.O.; FERREIRA, C.C.; MOREIRA, L.M.; ROMERO, N.R.; DIAS, L.A.; QUEIROZ, M.G.R.; LOPES, M.V.O.; FONTELES, M.M.F. Cardiovascular risk rate in hypertensive patients attended in primary health care units: the influence of pharmaceutical care. Braz. J. Pharm. Sci., v.51, n.3, p.617-627, 2015.

GERSTEL, E.; PATAKY, Z.; BUSNEL, C.; RUTSCHMANN, O.; GUESSOUS, I.; ZUMWALD, C.; GOLAY, A. Impact of lifestyle intervention on body weight and the metabolic syndrome in home-care providers. Diabetes Metab., v.39, n.1, p.78-84, 2013.

GILMARTIN, J.F.M. Using ethnographic approaches to explore care home medicine management systems. Res. Soc. Adm. Pharm., v.11, n.4, p.592-93, 2015.

GRUNDY, S.M. Pre-diabetes, metabolic syndrome, and cardiovascular risk. J. Am. Coll. Cardiol., v.59, n.7, p.635$643,2012$.

HAAHR, M. Random sequence generator. Available from: $<$ http://www.random.org/sequences/>. Accessed in: June $30,2014$.

HAMMAD, E.; YASEIN, N.; TAHAINEH, L.; ALBSOULYOUNES, A.M. A randomized controlled trial to assess pharmacist-physician collaborative practice in the management of metabolic syndrome in a University Medical Clinic in Jordan. J. Manag. Care Pharm., v.17, n.4, p.295-303, 2011.

JIN, J.; SKLAR, G.E.; SENOH, V.M.; LI, S.C. Factors affecting therapeutic compliance: A review from the patient's perspective. Ther. Clin. Risk Manag., v.4, n.1, p.269-286, 2008.

KAUR, J. A comprehensive review on metabolic syndrome. Cardiol Res Pract, v. 2014, p. 1-21, 2014.

MENDES, E.V. O cuidado das condições crônicas na atenção primária à saúde: o imperativo da consolidação da estratégia da saúde da família. Brasília: Organização PanAmericana da Saúde, 2012. 512p.

MOURÃO, A.O.M; FERREIRA, W.R.; MARTINS, M.A.P.; REIS, A.M.M.; CARRILLO, M.R.G.; GUIMARÃES, A.G.; SILVEIRA, L.E. Pharmaceutical care program for type 2 diabetes patients in Brazil: a randomised controlled trial. Int. J. Clin. Pharm., v.35, n.1, p.79-86, 2013. 
O’NEILL, S.; O’DRISCOLL, L. Metabolic syndrome: a closer look at the growing epidemic and its associated pathologies. Obesity Rev., v.16, n.1, p.1-12, 2015.

OCAN, M.; BBOSA, G.S.; WAAKO, P.; OGWAL-OKENG, J.; OBUA, C. Factors predicting home storage of medicines in Northern Uganda. BMC Public Health, v.14, p.650-657, 2014.

ORGANIZACIÓN PANAMERICANA DE LA SALUD. OPS/ OMS. Servicios farmacêuticos basados en La atención primaria de salud. Documento de posición de la OPS/OMS. Washington, DC: OPS, 2013. 91p.

PETERSON, G.M.; FITZMAURICE, K.D.; NAUNTON, M.; VIAL, J.H.; STEWART, K.; KRUM, H. Impact of pharmacist-conducted home visits on the outcomes of lipid-lowering drug therapy. J. Clin. Pharm. Ther., v.29, n.1, p.23-30, 2004.

PLASTER, C.P.; MELO, D.T.; BOLDT, V.; CASSARO, K.O.D.S.; LESSA, F.C.R.; BOËCHAT, G.A.P.; BISSOLI, N.S.; ANDRADE, T.U.D. Reduction of cardiovascular risk in patients with metabolic syndrome in a community health center after a pharmaceutical care program of pharmacotherapy follow-up. Braz. J. Pharm. Sci, v.48, n.3, p.435-446, 2012.

RUSSELL, C.L.; CONN, V.S.; JANTARAKUPT, P. Older adult medication compliance: Integrated review of randomized controlled trials. Am. J. Health Behav., v.30, n.6, p.636$650,2006$.

SANTSCH, V.; CHIOLERO, A.; BURNAND, B.; COLOSIMO, A.L.; PARADIS, G. Impact of pharmacist care in the management of cardiovascular disease risk factors: a systematic review and meta-analysis of randomized trials. Arch. Intern. Med., v.171, n.16, p.1441-1453, 2011.

SANTSCH, V.; CHIOLERO, A.; PARADIS, G.; COLOSIMO, A.L.; BURNAND, B. Pharmacist interventions to improve cardiovascular disease risk factors in diabetes: a systematic review and meta-analysis of randomized controlled trials. Diabetes Care, v.35, n.12, p.2706-2717, 2012.
SANTSCHI, V.; CHIOLERO, A.; COLOSIMO, A.L.; PLATT, R.W.; TAFFÉ, P.; BURNIER, P.M.; BURNAND, B.; PARADIS, G. Improving blood pressure control through pharmacist interventions: a meta-analysis of randomized controlled trials. J. Am. Heart Assoc., v.3, n.2, p.e000718, 2014.

SHIN, J.A.; LEE, J.H.; LIM, S.Y.; HA, H.S.; KWON, H.S.; PARK, Y.M.; LEE, W.C.; KANG, M.I.; YIM, H.W.; YOON, K.H.; SON, H.Y. Metabolic syndrome as a predictor of type 2 diabetes, and its clinical interpretations and usefulness. $J$. Diabetes Investig., v.4, n.4, p. 334-343, 2013.

SINO, C.; BOUVY, M.; SCHOP, I.; JANSEN, P.A.F.; EGBERTS, T.C.G.; SCHUURMANS, M. Signs and symptoms indicative of potential adverse drug reactions in homecare patients. J. Am. Med. Dir. Assoc., v.14, n.12, p.920-925, 2013.

SORENSEN, L.; STOKES, J.A.; PURDIE, D.M.; WOODWARD, M.; ROBERTS, M.S. Medication management at home: Medication-related risk factors associated with poor health outcomes. Age Ageing, v.34, n.6, p.626-632, 2005.

WAL, P.; WAL, A.; BHANDARI, A.; PANDEY, U.; RAI, A.K. Pharmacist involvement in the patient care improves outcome in hypertension patients. J. Pharm. Pract. Res., v.2, n.3, p.123-129, 2013.

WHOQOL GROUP. The World Health Organization quality of life assessment (WHOQOL): position paper from the World Health Organization. Soc. Sci. Med., v.41, n.10, p.1403-1409, 1995.

WIECZORKIEWICZ, S.M.; KASSAMALI, Z.; DANZIGER, L.H. Behind closed doors: medication storage and disposal in the home. Ann. Pharmacother, v.47, n.4, p.482-489, 2013.

ZERMANSKY, A.G.; ALLDRED, D.P.; PETTY, D.R.; RAYNOR, D.K.; FREEMANTLE, N.; EASTAUGH, J.; BOWIE, P. Clinical medication review by a pharmacist of elderly people living in care homes - randomised controlled trial. Age Ageing, v.35, n.6, p.586-591, 2006.

Received for publication on $09^{\text {th }}$ May 2016 Accepted for publication on $20^{\text {th }}$ January 2017 